\title{
Diretrizes estratégicas para ciência e tecnologia em recursos hídricos no brasil
}

\section{Carlos E. M. Tucci \\ Oscar M. Cordeiro}

RESUMO: U m dos principais componentes da gestão dos recursos hídricos são os investimentos em Ciência e Tecnologia. 0 desenvolvimento do conhecimento é a base do desenvolvimento sustentável e responsável. Recursos Hídricos. Esta é uma área com características interdisciplinares e interface com as diferentes áreas do conhecimento que procuram entender os processos naturaise antrópicos. A construção dosfocosou prioridades é um exercício que engloba ciência básica e aplicada interdisciplinares, o uso integrado dos recursos hídricos e o desenvolvimento sustentável.

Neste artigo são apresentadas as bases das diretrizes estratégicas utilizadas no Brasil em Ciência e Tecnologia em Recursos Hídricos que vem apoiando o investimento do Fundo Setorial de Recursos Hídricos CTH idro tornado operacional setembro de 2001 e gerenciado pelo MCT M inistério de Ciência e Tecnologia do Brasil.

0 fundamento principal das diretrizes estratégicas foi o de investir em pesquisa dentro uma visão orientada ao problema em contraposição ao tradicional investimento na demanda espontânea de pesquisadores que pulverizam os recursos em conteúdos que muitas vezes retratam mais os interesses da literatura internacional.

PALAVRAS-CHAVE: Estratégia, recursos hídricos, pesquisa.
ABSTRACT: O ne of the main aspects of water resources management is the investment in Science and Technology. Development of knowledge is important for sustainable water resource management. It is an interdisciplinary area of knowledge and has many interfaces with other areas of natural resources. I dentification of the main issues for research is an exercise that requires basic and applied resear$c h$, interdisciplinary and integrated use of water resources.

This article presents the strategic framework used in Brazil for Science and Technology in Water Resources that supports the Sectorial Water Resource Research Fund which has been operational since September of 2001 and is managed by the Ministry of Science and Technology of Brasil.

The approach established for the Strategic Framework wasto develop its investments in the country-oriented problems instead of investing in researcher demand which is more often related to international research issues.

KEY-WORDS: Strategy, water resources, research.

\section{INTRODUÇÃO}

A política de investimento em Ciência eTecnologia no Brasil teve impulso em 2000 com a criação de Fundos Setoriais de Pesquisa que retiram recursos de setores da sociedade para investimento em $C \&$ T. EstesFundosforam criados para incentivar o desenvolvimento científico e tecnológico em áreas estratégicas e cons- truir uma nova forma de financiamento de investimento em C\&T. Os Fundosfinanciam desde "encontros, congressos, publicações, auxílios individuais, infra-estrutura depesquisa, bolsas de formação e de fomen to tecn ológico, projetos cooperativos entre u niversidades e empresas, rede cooperativas, en tre entidades de pesquisa, até grandes projetos estrutu- 
rantes." (MCT, 2000) . O primeiro Fundo criado foi o de Petróleo, seguido por váriosoutrosfundos, que atualmente totalizam 14.

O Fundo de Recursos Hídricos (CTHidro) foi criado por Lei 9993 de 24 de julho de 2000 (Brasil, 2000) e regulamentado pelo decreto n. 3874 de 19 de julho de 2001 (Brasil, 2001a). Os objetivos do Fundo foram estabelecidos na referida lei e são os seguintes: "financiamento de projetos científicos e de desen volvimen to tecn ológico, destinados a aperfeiçoar os diversos usos da água, de modo a garantir à atual eàs futuras geraçôes alto padrão de qualidade, utilização racional e integrada com vistas ao desenvolvimento sustentável eà preven ção e defesa contra fenômenos hidrológicos críticos ou devido a o u so in adequado de recursos natu rais."

O s recursos são obtidos à partir da compensação financeira da U sinas Hidrelétricas, que destina $6 \%$ do valor da energia na U sina para compensar municípios, Estados e União pela inundação de terras produtivas. Do total cobrado, 4\% são destinados para C \& T e funcionamento do Fundo de Pesquisa. Este valor representa da ordem de US \$ 10 milhões por ano.

O CTHidro é administrado por um comitê gestor presidido pelo MCT - Ministério de Ciência e Tecnologia (Brasil, 2001b) e formado por representantes das entidades de fomento a pesquisa: CN Pq Conselho Nacional de Desenvolvimento Científico e Tecnológico e FINEP Financiadora de Estudos e Projetos; $\mathrm{M} \mathrm{i-}$ nistériose Agências de Governo: Ministério de Meio Ambiente, representado pela Secretaria de Recursos Hídricos, Ministério de Energia e ANA Agência Nacional de Águas; um representante da comunidade científica e outro das empresas. Inicialmente até abril de 2003 o CTH idro tinha um secretário técnico e outro adjunto (autores do artigo) e atual mente um grupo de técnico de apoio com representantes das entidades de $C \& \mathrm{~T}$. 0 primeiro comitê gestor foi indicado em 30 de agosto de 2001.

Em janeiro de 2001 iniciaram as discussões para preparação das bases do CTH idro que são o documento de diretrizes estratégicas e o Plano Pluri-anual de Aplicação PPA (MCT,2001) . Neste artigo são apresentados: os elementos básicos que levaram a construção das diretrizesestratégicas, aprimoradospela discussão em vários workshops com a comunidade científica no período de fevereiro a setembro de 2001; os mecanismos utilizados e as prioridades desenvolvidas em programas e prospecções e um resumo dos investimentos realizados.

\section{SÍNTESE EVOLUTIVA DOS RECURSOS HÍDRICOS}

\section{Histórico e tendência}

O século vinte foi palco de importantes transformações nos processos adotados pela sociedade para aproveitamento dos recursos hídricos. De um uso local e incipiente no início do século, passou-se a um uso intenso e setorial, até se buscar, ao final do século XX, implementar o conceito de uso múltiplo, integrado e sustentável da água.

Logo após a 2a Guerra Mundial, houve um período de grandes investimentos em infraestrutura, visando recuperar os países que sofreram com o conflito, seguido por um período de crescimento econômico e populacional significativo. Esse perío do foi caracterizado por forte industrialização e crescimento das áreas urbanas, o que levou ao início da crise ambiental do final de século $X X$, como resultado da degradação das condições de vida da população e dos sistemas naturais. No início da década de 70 iniciou a mobilização social para controle desses impactos através das primeiras legislaçõesambientais em países desenvolvidos. Foi uma década de maciços investimentos no tratamento de esgoto das cidades e das indústrias nos referidos países. Nos anos 80 , o mundo deparou-se com um grande divisor na percepção dos limites dos impactos ambientais, que foi 0 acidente da U sina Nuclear de Chernobyl, na antiga U nião Soviética. No meio científico, já se sabia da interação global de diversos efeitos da poluição. No entanto, pela primeira vez, a opinião pública confrontava-se com uma situação em que o ambiente de cada cidadão não era delimitado pelasfronteiras de sua região, mas que havia uma fortíssima interação ambiental global. O bservou-se, também, o início de gran de pressão sobre osinvestimentos internacionais em hidrelétricas em áreas como a Amazônia, região identificada pelo seu papel de destaque no processo de equilíbrio climático. No Brasil, pelas pressões externas, 
foram eliminados os empréstimos internacionais para construção de hidrelétricas, com grande impacto na capacidade de expansão do sistema elétrico no Brasil. N essa década, também, foi aprovada a legislação ambiental brasileira. Os anos 90 foram marcados pela idéia do desenvolvimento sustentável, fruto do equilíbrio entre o investimento no crescimento dos países e a conservação ambiental. Tornou-se clara a necessidade do aproveitamento dos recursos hídricos ocorrer de forma integrada, com múltiplos usos. No que se refere à poluição das águas, iniciou-se, nos países desenvolvidos, o controle da poluição difusa de origem urbana e agrícola. Os empréstimos de organismosinternacionais no Brasil que, no passado, privilegiavam, principalmente, o setor energético, mudaram para a melhoria sanitária e ambiental das cidades, iniciando-se com as grandes metrópoles brasileiras. Esse período foi marcado no Brasil pela aprovação da legislação nacional de recursos hídricos em 1997, pela implantação do sistema nacional de gerenciamento de recursos hídricos, o mesmo tendo ocorrido em vários Estados brasileiros ao longo da década.

O início deste novo século (e milênio) tem se caracterizado internacionalmente, pela busca de uma maior eficiência e conservação no uso dos recursos hídricos, tendo como base os princípiosbásicosaprovadosna Rio 92. No Brasil o processo institucional tem avançado com a criação da Agência Nacional de Águas, início da cobrança pelo uso da água e pela poluição gerada. Esse cenário se mostra promissor, uma vez que preconiza a participação de diferentes atores sociais no processo decisório do uso dos recursos hídricos e sua conservação.

\section{Ciência e Tecnologia}

Até a década de 70 do século vinte, os aspectostécnico-científicos de recursos hídricos eram respondidos, isoladamente, por engenheiros civis, quando se tratava de construir uma barragem, um canal, a drenagem de uma bacia; por engenheiros sanitários e civis quando se tratava de um sistema de água e esgoto; por químicose biólogos, no caso do desenvolvimento de processos de tratamento de água e esgoto; por agrônomos, quando se tratava de irrigação ou programas de conservação do solo; por geólogos quando se tratava de obter água subterrânea; por meteorologistas para prever as condições de tempo e clima, etc.

Definiam-se, assim, sistemas de intervenção limitados pelo espaço e pelas áreas do conhecimento e por objetivos específicos. 0 desenvolvimento em $C \& T$ era ditado, até então, tanto por uma visão setorial de aproveitamento da água quanto por uma ótica de controle da poluição e de proteção ambiental. Devido à evolução no desenvolvimento industrial e urbano, assim como na exploração dos recursos naturais, ficou evidente que o ambiente, ora em desequilíbrio, necessitava de uma avaliação mais precisa e integral dos processos e impactos, buscando-se evitar prejuízos que comprometessem a sustentabilidade da própria sociedade.

Até os anos 70, os resultados da ação do homem sobre o meio ambiente eram vistos so b a ótica estrita da escala local, isto é, de uma cidade, de um trecho de rio ou de uma área irrigada. Atualmente, os problemas devem ser vistos na escala da bacia hidrográfica. Alguns problemas expandem-se até a escala do país e do globo terrestre, em decorrência dospotenciaisefeitosna modificação tanto do uso do solo e quanto do clima, e de sua variabilidade. A complexidade do gerenciamento dos sistemas hídricos cresce devido à diminuição da disponibilidade dos recursos hídricose ao aumento da deterioração da qualidade da água nos diferentes sistemashídricos (rios, lagos, açudes, represas, aqüíferos, estuários e águas costeiras) com maior ocorrência de conflitos no aproveitamento da água. Além disso, há o aumento do interesse público no impacto dosaproveitamentoshídricossobre o meio ambiente. 0 planejamento da ocupação da bacia hidrográfica é uma necessidade em uma sociedade com usos crescentes da água, e que tende a ocupar a bacia de forma desordenada, inclusive avançando so bre as áreas de inundação, danificando ainda maiso seu meio ambiente.

0 desenvolvimento em C\&T incorpora, assim, preocupações de natureza multi-setorial no uso de água e de busca de soluções sustentáveis. A necessidade da integração é, portanto, um fato. No entanto, a formação técnica e profissional em Recursos Hídricosocorre, quase que exclusivamente, por meio de progra- 
mas de pós-graduação, no âmbito das áreas de engenharia civil. A maioria desses programas de pós-graduação se desenvolve voltando-se, primordialmente, para aspectos setoriais dos usos dos recursos hídricos como energia, água potável, saneamento e irrigação. $\mathrm{Na}$ última década, alguns programas voltaram-se para 0 desenvolvimento de pesquisas de âmbito ambiental, criando programas com características interdisciplinares.

\section{DESAFIOS E OPORTUNIDADES}

O s principais desafios de $C \& T$ relacionamse à busca de soluções sustentáveis para problemas de: escassez de água, excesso de água, deterioração da qualidade da água, percepção inadequada de gestores e do público em geral sobre a gravidade da questão da água, fragmentação e dispersão das ações de geren ciamento dos recursos hídricos, fontes de financiamento insuficientes para a resolução dos problemas relativos aos recursos hídricos, conflitos potenciais em rioscompartilhados por mais de um Estado ou país e perspectivas de mudanças climáticas na Terra que afetarão a distribuição e a disponibilidade de água.

\section{Visão Conceitual}

Como organizar os focos de pesquisa numa área tão interdisciplinar? É possível escolher as disciplinas do conhecimento como Hidrologia, H idráulica, Meteorologia, Qualidade da Água, entre outras e suas sub-divisões. De outro lado se o foco é a realidade do país pode-se escolher os principais biomas brasileiroscomo: Amazônia, Pantanal, Cerrado,Semi-árido, Costeiro, Sul e Sudeste. Alternativas de foco podem ser os sistemas hídricos como: rios, reservatórios, aqüíferos e bacias hidrográficas como muitos visualizam a gestão dos recursos hídricos. Olhando pelo sócio econômico os focos podem ser: energia, agricultura, meio ambiente, transporte, entre outros. Como se observa, todas estas linhas têm seu atrativo próprio, mas nenhuma delas atende o conjunto das preocupações de desenvolvimento de $C \& T$. De outro lado, considerando que o CTH idro foi criado para investir no conhecimento que apóie a melhoria da qualidade de vida da população e na conservação ambiental, é natu- ral que os seus investimentos sejam orientados para a solução de problemas da sociedade (problemoriented).

0 investimento tradicional em pesquisa vinha ocorrendo de forma pulverizada e dentro dos focos de interesses dos pesquisadores que nem sempre tinham componentes integradores e voltados para problemas críticos da sociedade. A figura 1 retrata de forma figurativa os vários componentes e caracteriza a gestão dos recursos hídricos e o foco dos investimentos para os principais problemas nacionais.

Conceitualmente o fundo busca o seguinte: (a) criar uma base de investimento permanente no qual a pesquisa tenha sustentabilidade para se desenvolver; ( $b$ ) desenvolver o foco de pesquisa para problemas de sociedade, convidando ospesquisadores a buscar solução para osmesmos; (c) concentrar esforços para a busca de inovação em $C \&$ T que alavanque o desenvolvimento social e econômico e garanta a sustentabilidade ambiental.

FIGURA 1.

Visão dos focos de pesquisa em Recursos Hídricos

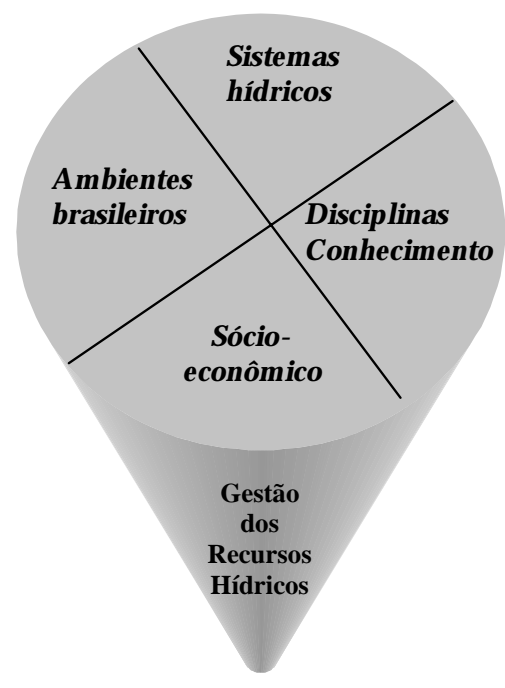




\section{Desafios}

Os grandes desafios que necessitam investimento de pesquisa em ciência e tecnologia e inovação em recursos hídricos no país envolvem os vários componentes citados nos itens anteriores e podem ser representados por uma tipologia que privilegie a visibilidade social. Para chegar aos referidos temasfoi realizada a seguinte pergunta: Q uais são os principais problemas de recursos hídricos no país visto pela maioria das pessoas? Estes aspectosforam elencados, discutidos e aprimorados e são relacionados a seguir:

\section{Sustentabilidade hídrica de regiões semi-áridas}

As regiões semi-áridas geralmente possuem grande fragilidade quanto à sua sustentabilidade hídrica. Poucos anos com disponibilidade hídrica fazem com que a população se estabeleça para, logo em seguida, quando ocorrem os longos períodos secos e os prejuízos inevitáveis, haja migração para outras áreas com forte empobrecimento da região e.

As conseqüências desses eventos extremos, sob o ponto de vista físico e climático, dão-se sobre saúde, trabalho e habitação da população, comprometen do a sustentabilidade da região. Contribuem, também, para isso, processos de degradação do solo e a desertificação.

0 desafio do desenvolvimento científico e tecnológico é o de dispor de elementos que criem condições para a permanência da população na região, melhorando suas condições econômicas, e também suas condições de educação, saúde, trabalho e habitação. Para isso, é preciso aumentar a disponibilidade hídrica por meio de técnicas inovadoras como novas formas de exploração de água subterrânea no cristal ino, coleta e armazenamento da água da chuva em cisternase açudes, processos de dessalinização, processos integrados de gestão da demanda e de racionalização do uso da água, controle e melhoria da qualidade da água e melhoria da previsão climatológica.

\section{Água e gerenciamento urbano integrado}

0 crescimento das cidades tem causado impactos significativos sobre o meio ambiente e, com isso, a população sofre com o comprome- timento do abastecimento público, a piora das condições de qualidade da água, as inundações, a má gestão dos resíduos sólidos, entre outros.

A falta de integração na gestão desses problemas, principalmente devido à setorização das ações públicas, tem sido uma das grandes causas do agravamento das condições hídricas em áreas urbanas. Os principais impactos verificados sobre os sistemas hídricos das cidades brasileiras são os seguintes: contaminação dos mananciais urbanos, como conseqüência da poluição dos sistemas hídricos e da ocupação desordenada das áreas de proteção de mananciais, levando à redução da disponibilidade hídrica; falta de tratamento e de disposição adequada de esgoto sanitário, industrial e de resíduos sólidos; aumento das inundações e da poluição devido à drenagem urbana deficiente; ocupação das áreas de risco de inundação, com graves conseqüências para a população; redução da disponibilidade hídrica.

O principal desafio é a busca de soluções integradas e economicamente sustentáveis. 0 desenvolvimento tecnológico deve buscar visão integrada para proteção de mananciais; racionalização do uso da água, com programas de redução de consumo; reuso da água, equipamentos de menor consumo; sistemas eficientes de tratamento de água, adequados à realidade local; sistemas de controle da poluição que melhorem a qualidade da água; controle das inundaçõese priorizar o planejamento urbano que conserve 0 ambiente e controle a disposição dos resíduos sólidos.

\section{Gerenciamento dos impactos da variabilidade climática sobre sistemas hídricos e a sociedade}

São significativos os efeitos da modificação do uso do solo e da variabilidade climática de curto e médio prazo sobre a bacia hidrográfica e sobre as atividades humanas. 0 conhecimento desses impactos sobre os sistemas hídricosé, ainda, limitado. Dessa forma, o gerenciamento integrado dessa questão praticamente não existe.

Existem várias características desse problema que são essencialmente brasileiras como a operação e a garantia do sistema energético e o comportamento dos grandes ecossistemas 
como o Pantanal e a Amazônia. Além disso, para melhor gerenciar conflitos de uso da água como, por exemplo, entre irrigação, energia, navegação fluvial, controle de inundações e proteção ambiental, é essencial o conhecimento antecipado do comportamento hídrico desses sistemas.

Os desafios para a ciência são a avaliação integrada dosprocessos meteorológicos, hidrológicos e dos ecossistemas sujeitos à variabilidade climática; desenvolvimento de modelagem desses processos integrados e a avaliação e mitigação dos cenários de desenvolvimento das regiões brasileiras.

\section{U so e conservação do solo e de sistemas hídricos}

No desenvolvimento agrosilvopastoril, a partir da ocupação dos espaços naturais em diferentes partes do país observam-se vários impactos, tais como: a erosão do solo e produção de sedimentos que se depositam nos rios, agregados a pesticidas; a própria degradação da superfície do solo com impacto local e a jusante da bacia; a drenagem e o conflito pela água em áreas de banhado, que representam ecossistemas a serem conservados como o Pantanal, Taim, entre outros; o desmatamento de extensas áreas com conseqüências importantes sobre o ciclo hidrológico; a redução da proteção das áreas marginais de rios, reservatórios, lagos, etc.; o uso intensivo da irrigação em certas regiões agrícolas do país, com ocorrência de uma série de conflitos entre a irrigação e outros usos da água e mesmo conflitos de irrigantes entre si.

O conhecimento quantitativo dos efeitos da ação antrópica sobre ecossistemas brasileirosé, ainda, limitado. Necessita-se de monitoramento e metodologias robustas que permitam uma adequada avaliação dos processos nas diferentes escalas de comportamento dos sistemas hídricos, além de práticas adequadas de gestão.

O sdesafios dessa linha são o desenvolvimento de tecnologias de aumento da produtividade dos sistemas agrossilvopastoris que contribuam para o ordenamento sustentável do espaço rural e que aumentem a eficiência do uso da água, mantendo a conservação do solo. Incluem-se, aqui, a avaliação e a mitigação dos impactos do desmatamento e das queimadas, particularmente em relação aos impactos sobre as áreas de proteção de mananciais.

\section{Prevenção e controle de eventos extremos}

Tanto as enchentes como as estiagens produzem importantes impactos sócio-econômicos. N esses processos, é importante desen volver mecanismos que permitam minimizar esses impactos. A convivência com esses processos naturais geralmente não encontra na sociedade um planejamento adequado para enfrentar as situações de emergência e nem mesmo mecanismos de previsão de ocorrência dessas situações.

São considerados eventos extremos a ocorrência de estiagem, das cheias, de incêndios florestais, entre outros. O desafio associado a esse tipo de intervenção envolve o desenvolvimento de sistemas de previsão de eventos extremos, de ações de planejamento preventivas necessárias para a mitigação dosimpactose do gerenciamento dos conflitos resultantes da ocorrência desses eventos.

\section{U sos integrados dos sistemas hídricos e conservação a mbiental}

A Agenda 21 e a lei n. 9433 de 08/ 01/ 97 que institui a Política Nacional de Recursos H ídricos estabelecem como prioridade o uso múltiplo dos recursos hídricos. Entre o objetivo e a prática existe uma grande distância em função de diferentescondicionantesregionais, econômicos, sociaise culturais. 0 uso da água tem sido essencialmente setorial e quando existe um uso suplementar, esse se dá, geralmente, de forma marginal.

O uso integrado não é somente a integração de usos, mas também a integração dos diferentes sistemas hídricos dentro da bacia hidrográfica. Cada sistema não pode ser visto isoladamente, mas dentro de um mesmo conjunto de sistemas que, de alguma forma, interagem no funcionamento e podem propiciar um melhor uso da água. A prática, além de setorizada em termos de uso, tem a visão essencialmente local.

O desafio é o de criar tecnologias que permitam viabilizar o conjunto de planejamento, projeto e operação de sistemas hídricos que 
compatibilizem de forma sustentável e adequada diferentes usos no conjunto da bacia ou região hidrográfica.

\section{Qualidade da água dos sistemas hídricos}

Um dos maiores problemas que o setor de recursos hídricos hoje enfrenta é o da redução da disponibilidade hídrica devido à degradação da qualidade da água dos rios, lagos e aqüíferos. Durante muito tempo, o controle da qualidade da água foi visto apenas de forma setorial, intervindo-se, prioritariamente, no efluente da indústria e nos efluentes domésticos, geralmente sem tratamento. A indústria foi fiscalizada e obrigada a melhorar seu efluente. O poder público tem buscado financiamento para os efluentes domésticos, mas, na ótica de gestão de bacias hidrográficas, apenas essa ação não é suficiente. Juntam-se a essa fonte de poluição, ascargas difusas de origem urbana e rural, além da poluição oriunda da mineração.

Para a melhoria da qualidade da água dos rios é necessário identificar as cargas das bacias, identificar os locais críticos e investir na redução dessas cargas. O levantamento de informações, a fiscalização e o monitoramento dosriossão essenciais para entender osimpactos e sobre eles atuar.

Os desafios deste componente são o de desenvolver metodologias eficientes para levantamento das cargas das bacias, para fiscalização, monitoramento e simulação dos processos que permitam a adequada gestão dos recursos hídricos. Nesse processo é essencial 0 desenvolvimento de infra-estrutura de laboratóriose equipamentos que permitam a identificação das condições de qualidade da água.

\section{Gerenciamento de bacias hidrográficas}

A implantação dos mecanismos e instrumentos técnicos e institucionais para o gerenciamento dos recursoshídricos, conforme a Lei 9.433/97, requer desenvolvimento de metodologia de caráter científico, tecnológico e institucional, que permita ao sistema alcançar plenamente seus objetivos.

Alguns dos desafios são: o desenvolvimento de sistemas de suporte à decisão dos sistemas de outorga para uso da água, tanto para capta- ções como para lançamentos; sistemas de cobrança pelo uso da água, com as respectivas avaliações econômicas necessárias; metodologia de enquadramento dos corpos de água, com vistas à integração plena da gestão quantidade-qualidade da água e dosmecanismos de participação pública.

\section{E studo do comportamento dos sistemas hídricos}

O entendimento do comportamento hidrológico na bacia hidrográfica, que envolve processos químicos, físicos e biológicos, é essencial para fazer face aos demais desafios aqui apresentados.

A diversidade dos ecossistemas brasileiros sujeitos às diferentes ações antrópicas se caracteriza por singularidades que necessitam ser compreendidas para buscar a sustentabilidade dosecossistemas. A quantidade de informações existente sobre esses diferentes sistemas é limitada no país, o que tem dificultado o seu gerenciamento em bases científicasadequadas.

Os desafios deste componente são de identificar as necessárias características-chave relacionadas a esses sistemas e de monitorar na forma de projetos-piloto representativos as variáveis explicativas criando uma base concreta para as ações públicas e privadas no uso e conservação dos sistemas hídricos nos diferentes biomas brasileiros.

\section{U so sustentável de recursos hídricos costeiros}

No Brasil, as características complexas da Zona Costeira são acentuadas pela sua imensa extensão, de cerca de $8.500 \mathrm{~km}$ ao longo de sua linha de litoral. N uma estreita faixa terrestre da zona costeira se concentra, aproximadamente, mais de um quarto da população brasileira, resultando numa densidade demográfica de cerca de 87 hab./ km² índice cinco vezes superior à média do território nacional.

Por isso é importante dar especial atenção ao uso sustentável dos recursos costeiros, com planejamento integrado da utilização de tais recursos, visando o ordenamento da ocupação dos espaços litorâneos. A Zona Costeira abriga um mosaico de ecossistemas de alta relevância ambiental, cuja diversidade é marcada pela transição de ambientes terrestres e mari- 
nhos com interações que the conferem um caráter de fragilidade e que requerem cuidados do poder público, conforme demonstra sua inserção na Constituição Brasileira como área de patrimônio nacional. Além disso, há uma tendência permanente ao aumento da concentração demográfica nas Zonas Costeiras. A saúde, o bem-estar e, em al guns casos, a própria sobrevivência das populações costeiras depende dos ecossistemas costeiros, incluindo áreas úmidas, regiões estuarinas, bacias de recepção e drenagem e as águas interiores próximas à costa. É fundamental um maior conhecimento sobre esses recursos naturaise do uso dos espaços costeiros para subsidiar e otimizar a aplicação dos instrumentos de controle e de gestão. Ciência, Tecnologia e Inovação podem contribuir para elevar a qualidade de vida da população, e a proteção do patrimônio natural. 0 desenvolvimento sistemático do diagnóstico da qualidade ambiental da Zona Costeira, identificando suas potencialidades, vulnerabilidades e ten dências predominantes, é elemento essencial para o processo de gestão. Ele permitiria efetivo controle sobre os agentes causadores de poluição ou degradação ambiental sob todas as suas formas, que ameacem a qualidade de vida na Zona Costeira e a produção e difusão do conhecimento científico.

\section{Desenvolvimento de Produtos e Processos}

Para enfrentar todos os desafios anteriormente descritos haverá enorme potencial de geração de produtos e processos que, não só contribuam para a solução de problemas específicos, mas permitam a expansão das suas aplicações para todo o país de forma bastante eficiente. Esse item específico de desenvolvimento refere-se à criação de novas tecnologias que poderão resultar em produtos comercializáveis, quer sob a forma de softwares e patentes, quer sob a forma de equipamentos.

U ma das formas de aumento de produtividade e maior utilização das tecnologias é o de criação de softwares que permitam o gerenciamento hídrico e uma maior transferência de tecnologia ao setor produtivo. Além disso, o desenvolvimento desses programas tem um potencial importante de geração de uma linha de serviços dentro do país em função da sua diversidade de problemas. Como conseqüência natural desse processo é possível criar produtos para exportação onde problemas e ambientes semelhantes necessitam de ferramentas como as que potencialmente podem ser desenvolvidas para a realidade brasileira. Modelos de operação de grandes sistemas, sistemas de previsão e alerta, modelos de operação para a área de saneamento e drenagem, entre outros, podem estar nessa linha de produção.

0 mesmo ocorre com a área de desenvolvimento de equipamentos. A área de recursos hídricos se ressente de uma falta de capacidade de aprimoramento tecnológico no desenvolvimento de equipamentos que atendam seus vários setores como: monitoramento hidrológico e de qualidade da água; equipamentos para a produção de água, saneamento, equipamentos para tornar eficiente o uso e reduzir o consumo da água nos meios urbano, rural e na indústria e equipamentos de redução e controle da poluição.

Grande parte dos equipamentos hoje utilizadosé importada e, muitas vezes, não atende à realidade e aos condicionantes naturais do país. 0 investimento atual no setor é pequeno e são grandes os desafios para se criar uma base permanente de tecnologia para al avancar esse tipo de indústria dentro do país.

\section{Capacitação de recursos humanos}

O desenvolvimento e a preservação dos recursos hídricos dependem de profissionais qualificados para pesquisa, tomada de decisão e ações no setor. 0 foco da capacitação é voltado para: ampliar a capacidade de pesquisa em regiões carentes como o Norte do país para grupos de pesquisa voltad os para as diferentes realidades brasileiras e pelo menosnos primeirosanos de investimento em capacitação, a formação deve abranger todos os níveis, desde o nível técnico até a pós-graduação, passando por programas de especialização e de extensão, atingindo profissionais e também osparticipantes do processo decisório, como os membros de comitês e consel hos de recursos hídricos.

É imprescindível que essa formação se dê de forma integrada e multidisciplinar e voltada inicialmente para: (a) capacitação de pro- 
fissionais que atuem nos Estados ou no Governo Federal, no gerenciamento dos recursos hídricos de forma mais ampla, denominado curso de Gerenciamento de Recursos H ídricos; (b) para profissionais que atuem nos municípios e necessitem de um enfoque específico, relacionado com o gerenciamento dosrecursoshídricos municipais, denominado de curso de Gerenciamento H ídrico M unicipal; (c) capacitação de membros dos órgãos colegiados dos sistemas de recursos hídricos, para que conheçam as particularidades dos sistemas sobre os quais eles tomam decisões; (d) ao sistema formal de formação de pesquisadores.

O desafio de aumentar e melhor qualificar os quadros profissionais do país é imenso. 0 adequado desenvolvimento do setor somente se dará com a formação de equipes integradas, multidisciplinares e treinadas nas várias especificidades de sua região.

\section{Infra-estrutura de apoio à pesquisa e a o desenvolvimento}

Por muitos anos, a quantidade de recursos financeiros não permitiu o aumento da infraestrutura de pesquisa em recursos hídricos.
Devido à falta de recursos e à sua intermitência ao longo do tempo, a infra-estrutura para o setor de recursos hídricos tem ficado deteriorada e desatualizada, necessitando apoio significativo para se tornar moderna e poder criar uma base concreta para o desenvolvimento dos projetos das diferentes linhas de pesquisa do Fundo.

O sdesafiosenvolvem a modernização de laboratórios de qualidade da água, de hidráulica, sedimentos, solos, entre outros; laboratórios de aferição de equipamentos utilizados no monitoramento e no setor produtivo; monitoramento de áreas-piloto de processos e sistemas hídricos.

\section{ESTRUTURA DAS ÁREAS PRIORITÁRIAS}

As áreas prioritárias para financiamento de ações pelo CT-HIDRO são baseadas nos desafioscitadosanteriormente e organizadas segundo o seguinte:

Pesquisa e Desenvolvimento: visam à criação de conhecimento para solução de problemas existentes no gerenciamento dos recursos hídricos para a sociedade;

TABELA 1

Áreas Prioritárias para Financiamento de Ações pelo CTHidro (MCT,2001)

\begin{tabular}{|l|l|l|l|}
\hline $\begin{array}{l}\text { Categorias de } \\
\text { Intervenção }\end{array}$ & Áreas Prioritárias & Principais Problemas Observados & Objetivo da Intervenção \\
\hline $\begin{array}{l}\text { Pesquisa e } \\
\text { Desenvolvimento }\end{array}$ & $\begin{array}{l}\text { Sustentabilidade } \\
\text { hídrica de regiões } \\
\text { semi-áridas }\end{array}$ & $\begin{array}{l}\text { Limitações ao desenvolvimento devido à } \\
\text { falta de água para a população e para a } \\
\text { produção de alimentos }\end{array}$ & $\begin{array}{l}\text { Ampliar a disponibilidade hídrica } \\
\text { para os diferentes usos (superficial e } \\
\text { subterrâneo), com vista à melhoria } \\
\text { dos índices de desenvolvimento } \\
\text { humano. }\end{array}$ \\
\hline & $\begin{array}{l}\text { Água e o } \\
\text { gerenciamento } \\
\text { urbano integrado }\end{array}$ & $\begin{array}{l}\text { Saneamento ambiental inadequado, com } \\
\text { problemas de água, esgoto e drenagem } \\
\text { urbana, acarretando contaminação e } \\
\text { poluição de mananciais, ocorrência de } \\
\text { doenças e perda de qualidade de vida }\end{array}$ & $\begin{array}{l}\text { Racionalizar o uso urbano da água, } \\
\text { buscando melhoria da saúde e da } \\
\text { qualidade de vida das populações, } \\
\text { assim como a qualidade da água dos } \\
\text { mananciais. }\end{array}$ \\
\hline & $\begin{array}{l}\text { Gerenciamento dos } \\
\text { impactos da } \\
\text { variabilidade climática } \\
\text { sobre sistemas } \\
\text { hídricos e sociedade }\end{array}$ & $\begin{array}{l}\text { Incapacidade técnica e institucional para } \\
\text { se gerenciarem, de forma eficiente, os } \\
\text { efeitos da variabilidade climática na } \\
\text { sociedade, nas atividades humanas e no } \\
\text { meio ambiente }\end{array}$ & $\begin{array}{l}\text { Prevenir-se contra os de curto, } \\
\text { médio e longo prazos da variação } \\
\text { associado ao clima, por meio da ação } \\
\text { de previsão e planejamento. }\end{array}$ \\
& $\begin{array}{l}\text { Uso e conservação do } \\
\text { solo de sistemas } \\
\text { hídricos }\end{array}$ & $\begin{array}{l}\text { Erosão e sedimentação do solo, perda de } \\
\text { cobertura natural e revegetação } \\
\text { inadequados }\end{array}$ & $\begin{array}{l}\text { Desenvolver práticas de ocupação e } \\
\text { aproveitamento do espaço, com } \\
\text { conservação do solo e dos sistemas } \\
\text { hídricos. }\end{array}$ \\
\hline & $\begin{array}{l}\text { Usos integrados dos } \\
\text { sistemas hídricos e } \\
\text { conservação } \\
\text { ambiental }\end{array}$ & $\begin{array}{l}\text { Uso setorial dos recursos hídricos, } \\
\text { conflitos dos usos e impactos resultantes. }\end{array}$ & $\begin{array}{l}\text { Otimizar e racionalizar os usos } \\
\text { integrados dos sistemas hídricos com } \\
\text { o mínimo impacto ambiental. }\end{array}$ \\
\hline
\end{tabular}


(Tabela 1 - continuação)

\begin{tabular}{|c|c|c|c|}
\hline $\begin{array}{l}\text { Categorias de } \\
\text { Intervencão }\end{array}$ & Áreas Prioritárias & Principais Problemas Observados & Objetivo da Intervenção \\
\hline & $\begin{array}{l}\text { Prevenção e controle } \\
\text { de eventos extremos }\end{array}$ & $\begin{array}{l}\text { Fortes impactos sócio econômicos devido } \\
\text { a enchentes e secas em diferentes partes } \\
\text { do país. }\end{array}$ & $\begin{array}{l}\text { Minimizar o impacto dos eventos } \\
\text { extremos sobre a sociedade e o } \\
\text { ambiente, por meio da previsão e do } \\
\text { planejamento. }\end{array}$ \\
\hline & $\begin{array}{l}\text { Qualidade da água } \\
\text { dos sistemas hídricos }\end{array}$ & $\begin{array}{l}\text { Degradação dos mananciais devido à } \\
\text { incipiência de saneamento urbano e rural } \\
\text { e a outras formas de poluição }\end{array}$ & $\begin{array}{l}\text { Evitar e controlar o impacto das } \\
\text { diferentes ações nas bacias sobre a } \\
\text { qualidade da água dos sistemas } \\
\text { hídricos }\end{array}$ \\
\hline & $\begin{array}{l}\text { Gerenciamento de } \\
\text { bacias hidrográficas }\end{array}$ & $\begin{array}{l}\text { Limitações legais, técnicas, institucionais e } \\
\text { financeiras para implementar ações } \\
\text { integradas e eficientes de gestão de água }\end{array}$ & $\begin{array}{l}\text { Desenvolver mecanismos eficientes } \\
\text { para o gerenciamento de bacias e } \\
\text { regiões hidrográficas. }\end{array}$ \\
\hline & $\begin{array}{l}\text { Uso sustentável dos } \\
\text { recursos hídricos } \\
\text { costeiros }\end{array}$ & $\begin{array}{l}\text { Fortes impactos associados ao } \\
\text { desenvolvimento industrial e urbano, nas } \\
\text { áreas costeiras, com desaparecimento e } \\
\text { degradação de importantes ecossistemas }\end{array}$ & $\begin{array}{l}\text { Desenvolver conhecimento sobre os } \\
\text { ecossistemas costeiros e mecanismos } \\
\text { que compatibilizam ocupação, } \\
\text { aproveitamento e conservação dessas } \\
\text { áreas. }\end{array}$ \\
\hline Estudos de Base & $\begin{array}{l}\text { Comportamento dos } \\
\text { sistemas hídricos }\end{array}$ & $\begin{array}{l}\text { Lacunas no conhecimento do } \\
\text { comportamento dos sistemas hídricos, } \\
\text { impossibilitando processo eficiente de } \\
\text { gerenciamento dos recursos hídricos }\end{array}$ & $\begin{array}{l}\text { Ampliar o conhecimento sobre } \\
\text { comportamento dos biomas } \\
\text { brasileiros e de seus sistemas hídricos } \\
\text { para apoiar o desenvolvimento } \\
\text { sustentável }\end{array}$ \\
\hline $\begin{array}{l}\text { Produtos e } \\
\text { Processos }\end{array}$ & $\begin{array}{l}\text { Desenvolvimento de } \\
\text { produtos e processos }\end{array}$ & $\begin{array}{l}\text { Produtos e processos produtivos de } \\
\text { controle da emissão de rejeitos } \\
\text { incompatíveis com a realidade do país ou } \\
\text { com a sustentabilidade dos ecossistemas, } \\
\text { assim como dependência externa em } \\
\text { equipamentos, insumos e aplicativos }\end{array}$ & $\begin{array}{l}\text { Favorecer o fortalecimento da } \\
\text { indústria nacional de equipamentos e } \\
\text { de serviços para o atendimento às } \\
\text { demandas dos diferentes usos e da } \\
\text { conservação da água. }\end{array}$ \\
\hline Recursos Humanos & $\begin{array}{l}\text { Capacitação de } \\
\text { recursos humanos. }\end{array}$ & $\begin{array}{l}\text { Falta de profissionais capacitados em } \\
\text { todos os níveis do setor de recursos } \\
\text { hídricos como forte limitação ao } \\
\text { desenvolvimento do setor }\end{array}$ & $\begin{array}{l}\text { Formar o pessoal necessário para } \\
\text { atuar nas ações de pesquisa, } \\
\text { desenvolvimento e gestão do setor de } \\
\text { recursos hídricos }\end{array}$ \\
\hline Infra-estrutura & $\begin{array}{l}\text { Infra-estrutura de } \\
\text { apoio à pesquisa e ao } \\
\text { desenvolvimento } \\
\text { tecnológico }\end{array}$ & $\begin{array}{l}\text { Infra-estrutura de pesquisa c } \\
\text { desenvolvimento no setor, ainda limitada }\end{array}$ & $\begin{array}{l}\text { Implementar, ampliar, equipar e } \\
\text { modernizar centros de pesquisa e } \\
\text { laboratórios que atuam no setor de } \\
\text { recursos hídricos }\end{array}$ \\
\hline
\end{tabular}

Estudos de Base: são pesquisas voltadas para o conhecimento do comportamento dos processos hídricosnos biomas brasileiros sob condições naturais ou sujeitos a impactos antrópiCOS;

Produtos e Processos: criação de novos produtose processoscomercializáveis ou não, quer sob a forma de softwares e patentes, quer sob a forma de equipamentos;

Recursos H umanos: programas que qualifiquem profissionais para o desenvolvimento de ciência e tecnologia para receberem a transferência de conhecimento, com ênfase na difusão junto ao setor produtivo;

Infra-estrutura: desenvolver infra-estrutura que permita ampliar o conhecimento científico e tecnológico, no atendimento dosdiferentes projetos.
Na tabela 1 apresenta-se um resumo dessas áreas prioritárias, considerando-se a organização citada, definidas suas principais características e seus objetivos.

\section{PROSPECÇÃO}

Asprospecções dentro de recursoshídricos foram realizadas em dois níveis:

Prospectar (MCT, 2002) : que é uma ação de prospecção em diferentes áreas de $C \& T$ desenvolvido dentro do MCT com o objetivo de validar os temas identificados e verificar a tendência junto aos pesquisadores;

Prospecções aprovadas no comitê gestor: Dentro do CTH idro foram discutidas e aprovadas seis prospecções de temas identificados como relevantes, mas que necessitavam identificar os focos e mecanismos de investimentos. 


\section{Prospectar}

A síntese do projeto PROSPECTAR em RecursosH ídricos desenvolvido pelo MCT (2001) é apresentado a seguir. Na 1 a rodada de consultas à comunidade científica e tecnológica do setor, o tema foi subdividido, a partir da listagem de áreas de pesquisa da Plataforma Lattes, do CNPq, em 116 sub-temas, cada um contendo de um a quatro tópicos, totalizando 139 tópicos. Ao final dessa primeira consulta, da qual participaram 1.332 respondentes, foram sugeridos 442 novos tópicos, distribuídos em 97 subtemas. Para a 2 ${ }^{\mathrm{a}}$ rodada de consultas à comunidade, as instituições âncoras, auxiliadas por um comitê de triagem, procuraram consolidar os resultados parciais, eliminando repetições de tópicos, tópicos que não diziam respeito diretamente ao tema, etc., além de propor alguns novos temas. Os 218 tópicos de pesquisa resultantes desse processo de consolidação foram redistribuídosem 11 sub-temas, obtidos das áreas prioritárias de pesquisa descrita no item anterior. $\mathrm{Na}$ 3a rodada, conforme a metodologia Delphi, o mesmo conjunto de subtemas e tópicos foram reapresentados para as pessoas que responderam na rodada anterior, para que os mesmos revissem suas respostas, à luz do conjunto de respostas obtidasna 2 a rodada, confirmando-asou não. Nesse processo, participaram 228 pessoas, resultando daí um conjunto de respostas sobre 213 tópicos de pesquisa.

Os 11 subtemas de Recursos Hídricos estão representados nas Figuras 2 e 3 por suas posições médias em relação aos índices de Relevância e de Disponibilidade, bem como ao H orizonte de Realização. Estes índices foram obtidos a partir da média das respostas ponderadas pelo grau de conhecimento das pessoas que responderam sobre os tópicos específicos. 0 índice de Relevância agrega os três índices de efeito esperado levantadosnosquestionários: aumento da eficiência do sistema produtivo; melhoria da qualidade de vida da população; avanço do conhecimento científico e tecnológico. 0 índice de Disponibilidade agrega os três índices de disponibilidade utilizados na pesquisa: recursos humanos qualificados; infra-estrutura de pesquisa; capacitação tecnológica no setor produtivo. Estes índices agregados de Relevância e de Disponibilidade podem variar de -1 até +1 , representando os valores negativos uma condição desfavorável na opinião das pessoas que responderam; os vaIores positivos, uma condição favorável e o zero uma situação intermediária. O horizonte de realização, por sua vez, estabelece o ano em que, segundo estimativa dosque responderam a pesquisa, o sub-tema em média, ou cada tópico de per si, será concretizado.

O s sub-temas são apresentados na Figura 2 como um gráfico da Relevância (ordenada) em relação à Disponibilidade (abscissa), no qual o tamanho das esferas é proporcional ao número de tópicos do sub-tema. Pode-se constatar que os sub-temas de Recursos Hídricos foram em média avaliados pelos respondentes de modo muito favorável quanto a sua relevância.

Dez dosonze sub-temassituam-se entre 0,28 e 0,39 e o sub-tema "U so do Solo e os Sistemas Hídricos" separa-se dos demais com o valor 0,50 . Esta avaliação favorável parece refletir o destaque que a importância dos recursos hí-

FIGURA 2

Os sub-temas de Recursos Hídricos em relação ao índice de Relevância

(MCT, 2002)

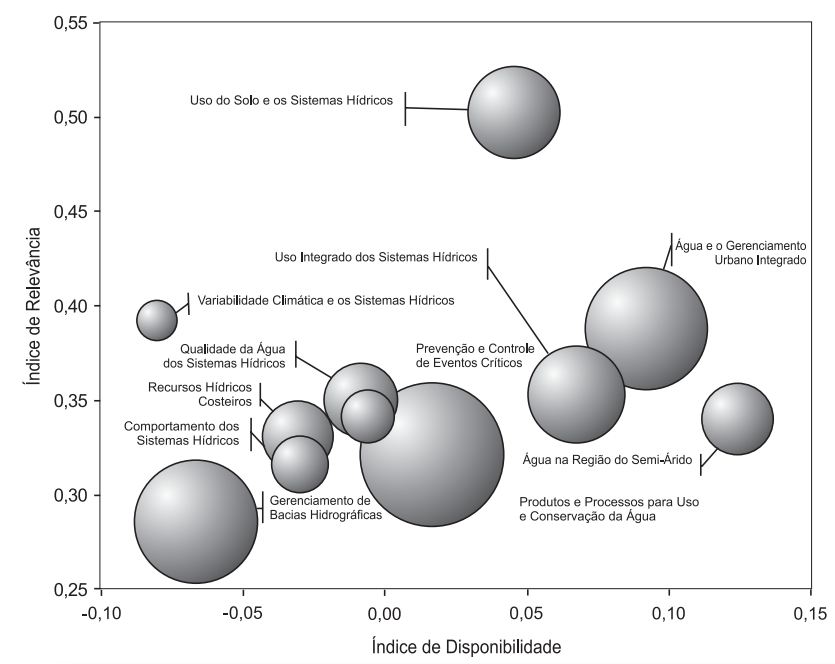


dricos como um todo vem recebendo no mundo e na sociedade brasileira. Quanto ao índice de Disponibilidade, a avaliação dos sub-temasfoi mais diferenciada, refletindo uma percepção de carências em recursos humanos, infra-estrutura e capacitação tecnológica em várias áreas de pesquisa.

Os índices variam entre $-0,08$ e $+0,12$, com seis sub-temas em situação desfavorável (valoresnegativos) e cinco em situação favorável (valores positivos). 0 número de tópicos por subtemas ( tamanho das esferas) revela três sub-temas preponderantes ("Produtos e Processos para U so e Conservação da Água" - 47 tópicos, "Gerenciamento de Bacias H idrográficas" - 34 tópicose "Água e Gerenciamento U rbano Integrado" - 34 tópicos), seguidos de mais dois subtemas intermediários ("U so I ntegrado dos Sistemas Hídricos" - 22 e "Uso do Solo e os Sistemas Hídricos" - 20). Estesnúmeros elevados de tópicosrefletem, no caso, a diversidade dosusos e dos instrumentos de gestão dos recursos hídricos, e de soluções na área dos produtos e processos voltados para o uso e gestão. 0 subtema "Variabilidade Climática e os Recursos Hídricos" ( com apenas quatro tópicos) é avaliado com alta relevância $(0,39)$, porém com baixa disponibilidade $(-0,08)$.

\section{FIGURA 3}

Os sub-temas de Recursos Hídricos em relação ao índice de Disponibilidade (MCT, 2002)

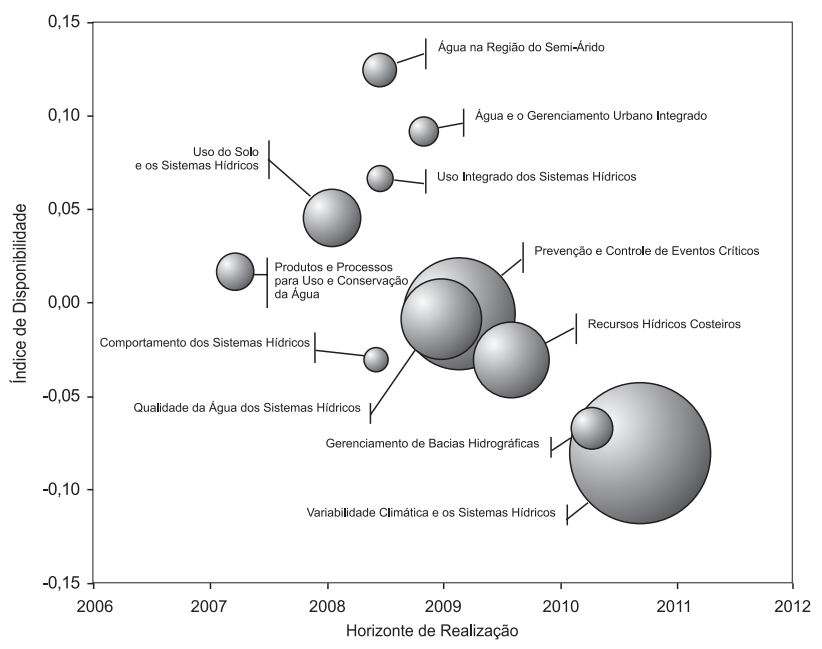

$\mathrm{Na}$ Figura 3 estão representados os mesmos sub-temas da figura anterior, relacionando os índices de Disponibilidade (ordenada) com o H orizonte de Realização (abscissa) . 0 tamanho das esferas, neste caso, é proporcional ao módulo do índice de Necessidade de Cooperação Internacional, ou seja, pode crescer entre zero e +1 (necessidade crescente de cooperação internacional; esferas mais escuras), ou crescer entre zero e - 1 (indicando necessidade decrescente de cooperação; esfera mais clara).

Os sub-temas com maior horizonte de realização são os que têm índice de disponibilidade mais desfavorável, e também maior necessidade de cooperação internacional. Por exemplo, Variabilidade Climática e os Sistemas Hídricos, Pre venção e Controle de Eventos Críticos e, em menor escala, Recursos H ídricos Costeiros e Qualidade da Água dos Sistemas H ídricos. O sub-tema Gerenciamento de Bacias H idrográficas, cuja realização foi estimada para concretizar-se em 2010, tem um índice de disponibilidade relativamente desfavorável $(-0,066)$, porém sua necessidade de cooperação é relativamente mais baixa $(0,038)$. U ma possível interpretação para este fato é a natureza local, ou mesmo "interna", dos problemas relacionadoscom o assunto. 0 sub-tema com menor necessidade de cooperação internacional é U so do Solo e os Sistemas H ídricos, único sub-tema de Recursos Hídricos com valor negativo deste índice. Apesar da baixa avaliação do índice de Disponibilidade deste subtema, verifica-se que a maior parte dos tópicos são propostos para uso amplo, referindo-se a tecnologias em princípio já dominadas no país, o que pode explicar a baixa necessidade de cooperação internacional. Dois sub-temas, Água na Região do Semi-árido e Água eo Gerenciamento urban o Integrado chamam a atenção pelo horizonte de realização dilatado em relação ao elevado índice de Disponibilidade.

\section{Prospecções aprovadas pelo comitê gestor}

O comitê gestor aprovou as seguintes prospecções para serem realizadas em 2003 (concluídos no início de 2004): Racionalização da água na 
agricultura; Saneamento; Qualidade da Água Superficial e Subterrânea, Clima e Recursos Hídricose produtos e Equipamentos. Este processo se baseia num documento de base preparado por um ou dois consultores, consulta a especialistas através de reuniões específicas, revisão e discussão em workshop conjunto no qual são definidos os focos, interfaces e mecanismos de investimentos. 0 workshop foi realizado em dezembro de 2003 e o documento final foi apresentado em fevereiro de 2004 (CGEE, 2004).

TABELA 2

Projetos aprovados em 2001 e 2002 (CGEE,2002)

\begin{tabular}{|lcc|}
\hline \multicolumn{1}{|c}{ Áreas Prioritárias } & $\begin{array}{c}\text { Número de } \\
\text { Projetos }\end{array}$ & $\begin{array}{c}\text { Proporção do total } \\
\text { dosecursos }\left(^{*}\right)\end{array}$ \\
\hline Sustentabilidade hídrica de regiões semi-áridas & 5 & 1,1 \\
Água e o gerenciamento urbano integrado & 57 & 33,6 \\
Gerenciamento dos impactos da variabilidade climática & 9 & 2,3 \\
sobre sistemas hídricos e sociedade & 27 & 8,1 \\
Uso e conservação do solo e de sistemas hídricos & 8 & 4,0 \\
Usos integrados dos sistemas hídricos & 1 & 0,4 \\
e conservação ambiental & 25 & 10,9 \\
Prevenção e controle de eventos extremos & 33 & 17,8 \\
Qualidade da água dos sistemas hídricos & 1 & 0,4 \\
Gerenciamento de bacias hidrográficas & 4 & 1,0 \\
Uso sustentável dos recursos hídricos costeiros & 6 & 1,8 \\
Comportamento dos sistemas hídricos & 221 & 0,7 \\
Desenvolvimento de produtos e processos & 10 & \\
Capacitação de recursos humanos & 305 & 100 \\
Outros & 407 & \\
\hline Total de bolsas para os projetos acima $(* *)$ & 712 & \\
\hline Total de projetos & \multicolumn{2}{l}{} \\
\hline Total &
\end{tabular}

${ }^{*}$ ) total investido de $\mathrm{R} \$ 42,8$ milhões, equivalentes a aproximadamente US $\$ 14,3$ milhões; $\left.{ }^{*}\right)$ incluídas as bolsas de mestrado e doutorado.

\section{PROGRAMAS, MECANISMOS E INVESTIMENTOS}

Dentro do PPA Plano Plurianual de Investimentos foram definidos Programas, que são ações específicas em setoresidentificados, prospeç̧ões onde devem ser investigados os focos de investimentos (ver item anterior). Os programas definidos foram: Capacitação, Águas urbanas, Gerenciamento dos Recursos Hídricos e Semi-Árido. Os mecanismos de investimentos utilizados foram desde a seleção de projetos específicos, investimento em rede de pesquisa como editais específicos dentro de linhas de pesquisa detal hadas. $\mathrm{Na}$ tabela 2 são apresentados resumos dos investimentos por tema. Deve-se considerar que foi escolhido um tema para cada projeto, mesmo que o mesmo incorpore mais de uma das áreas prioritárias. Por exemplo, no ambiente do semi-árido existem vários investimentos incorporados nas outras linhas como gerenciamento de recursos hídricos e capacitação.

Na figura 4 é ap resentada a distribuição dos recursos por região do país, mostrando a gran- 
FIGURA 4

Distribuição dos

investimentos aprovados

até 2002 (CGEE,2002).

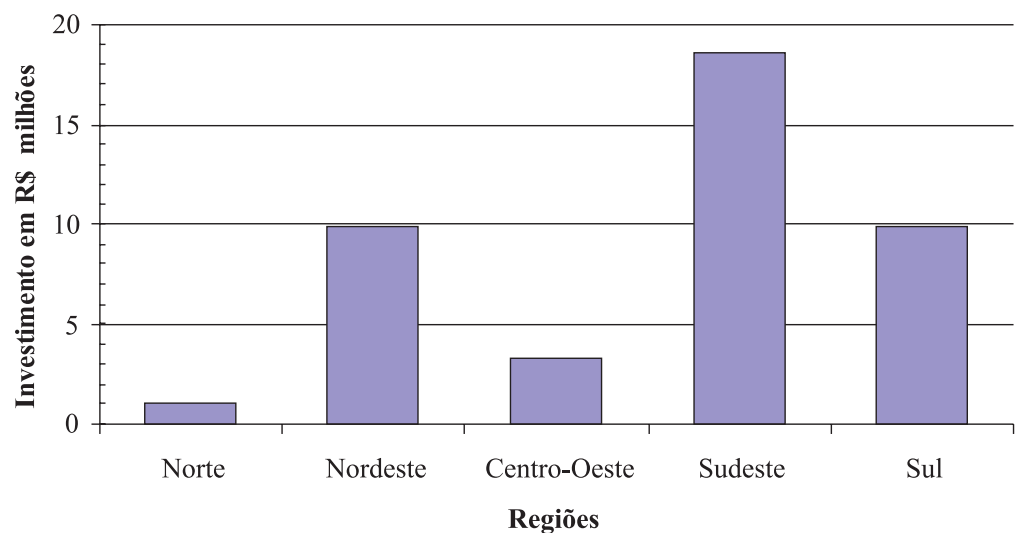

de lacuna que é a falta de projetos e investimentos na região Norte. Em termos legais 0 CTH idro deve aplicar no mínimo 30\% para Norte, N ordeste e Centro-O este. 0 que se observou é que o investimento se concentrou mais no N ordeste, dentro deste grupo.

Pode-se observar nos investimentos realizados que ficaram algumas lacunas em função dos seguintes fatores: (i) 0 pequeno investimento em algumas linhas se deve principalmente as áreas em que estão sendo realizadas prospecções como Produtos e Equipamentos, (ii) Qualidade da água; (iii) U ma das áreas que não possui investimento em prospecção e os investimentos são aproximadamente nulos se deve ao ambiente costeiro; (iv) Falta de investimentos na região devido a falta de grupos de pesquisas qualificados na área de recursos hídricos; (v) Faltam concretizar investimentos nos outros ambientes brasileiroscomo: Amazônia, Pantanal, Cerrado e Costeiro ( mencionado acima); ( vi) O seventos críticos relacionados com inundações e secas foram planejados dentro do programa de clima e recursos hídricos, mas os investimentos realizados se referem a projetos isolados.

\section{CONCLUSÕES}

A promoção de uma forte articulação entre o CTH idro e os Programas do Governo Federal provavelmente deverá pautar as ações do Fundo nos próximos anos. As ações do Fundo deverão unir-se ao esforço governamental em busca de soluções que minimizem a pobreza do país e que apóiem o seu desenvolvimento. Soluções estas que irão passar, muitas vezes, pelo equacionamento de questões ligadas a: ampliação da disponibilidade de água no semiárido brasileiro, soluções para o saneamento ambiental nas cidades: drenagem urbana, esgotamento sanitário, abastecimento de água (articulação com o Ministério das Cidades e com a Fundação N acional de Saúde); otimização do uso da água na agricultura (Ministério da Agricultura, Ministério do Desenvolvimento Agrário).

Deverá, ainda, ser fortalecida a articulação de ações promovida com a ANA (Agência Nacional de Águas) e a SRH (Secretaria de Recursos Hídricos) ligadas à implantação do Sistema Nacional de Gerenciamento de Recursos Hídricos; com a Agência $\mathrm{N}$ acional de Energia Elétrica (ANEEL) e com o Operador Nacional de Sistemas nos temas voltados ao monitoramento hidrológico, planejamento de usos múltiplos de reservatórios, dentre outros.

Por fim, a combinação de ações e recursos financeiros do CTH idro deverá se estender, também, a usuários dos recursos hídricos, fabricantes de equipamentos e empresas de engenharia, a exemplo da Carta-Convite lançada em 2002. A aproximação entre a iniciativa privada e a comunidade empresarial é vantajosa não apenas no sentido de ampliar o aporte de recursos destinados ao desenvolvimento científico e tecnológico, como também no sentido de aproximar pesquisadorese usuários dos resultados das pesquisas. 


\section{Referências}

BRASIL. 2000. Lei n. 9.984, de 17 de julho de 2000. Dispõe sobre a criação da Agência Nacional de Águas -ANA. Brasília: Senado Federal. 11p.

BRASIL. 2001a. Decreto n. 3874, de 19 de julho de 2001. Regulamenta o inciso v do artigo 1 da Lei n.8.001 de 13 de março de 1990 , e a Lei n.9.993 de 24 de julho de 2000. Diário Oficial da República Federativa do Brasil. Poder Executivo, Brasília, 20 jul. 2001.

BRASIL. 2001b. Portaria MCT n.386, de 30/08/2001. Brasília: Ministério de Ciência e Tecnologia. 3p.

BRASIL. Ministério de Ciência e Tecnologia. 2000. Fundos setoriais de desenvolvimento científico e tecnológico: uma estratégia de desenvolvimento. Brasília. 25p.

BRASIL. Ministério de Ciência e Tecnologia. 2001. Diretrizes estratégicas do CTHidro. Brasília: Centro de Gestão de Estudos Estratégicos. $75 p$.

BRASIL. Ministério de Ciência e Tecnologia. 2002. ProspeCTar: recursos hídricos. Brasília. 120p.

CENTRO DE GESTÃO DE ESTUDOS ESTRATÉGICOS. 2002. Relatório CTHidro 2001-2002. Brasília. 80p.

Carlos E. M. Tucci Instituto de Pesquisas Hidráulicas - Universidade Federal do Rio Grande do Sul; GWP - South America - Global Water Partnership - Porto Alegre, RS, Brasil (carlos.tucci@ufrgs.br)

Oscar M. Cordeiro UNB Universidade de Braślia - Brasília, DF, Brasil. (omcn@uol.com.br) 